\title{
Factors Facilitating and Forcing the Breast-Feeding to Tebessa (East City Algerian)
}

\author{
Salima Taleb ${ }^{1 *}$, Hayet Oulamara ${ }^{2}$, Abdel Nacer Agli $^{2}$ \\ ${ }^{1}$ Faculty of Natural and Life Science, Department of Natural Science and Life, University Cheikh Laarbi Tebessi, Tébessa, Algeria; \\ ${ }^{2}$ Nutrition and Food Technology Laboratory LNTA, Institute of Nutrition and Food Technology (INATAA), Mentouri University, \\ Constantine, Algeria. \\ Email: *talebsalima@yahoo.fr
}

Received January $5^{\text {th }}, 2011$; revised October $19^{\text {th }}, 2011$; accepted October $26^{\text {th }}, 2011$

\begin{abstract}
To estimate the situation of the breast-feeding, we made a survey (investigation) in the wilaya of Tébessa in Algeria. Our sample was chosen at random. He is constituted by 200 mothers and 200 children aged 0 to 24 month. A questionnaire, beforehand established, is subjected to the mothers. Our statistical analysis is based on the test of Chi2 and the calculation of the percentages. It emerges from our work that: the exclusive breast-feeding is practised by $50.50 \%$ of the cases. The breast-feeding is less practised by the salaried women $40.91 \%$. The practice of the exclusive feeding increases when the academic level of the mother decreases (50.80\% vs. $46.15 \%)$, the rate of the mixed feeding and the artificial feeding increases when the academic level increases. The circle of acquaintances plays an important role in the choice of the mode of feeding with $53.47 \%$ of the cases. The first food given to the Child within first hour which has followed the childbirth: the maternal milk with $66.5 \%$ was. The main causes of the stop of the breast-feeding are: the health of the woman, the incapacity of the milk, the resumption of work the aesthetics of the woman and the arien of a new pregnancy. $72.78 \%$, of the mothers have chooses the breast-feeding because it is better for the health of the child. The average duration of the feeding is of ( $4.68 \pm 4.437$ months) the day of the survey. A better information of the population about the feeding and a rationalization of the marketing of industrial milk, could help in a better promotion of the breast-feeding.
\end{abstract}

Keywords: Breastfeeding; Mothers; Children; PMI Tebessa (Algeria)

\section{Introduction}

Breastfeeding is recognized as the form of power best suited for infants and young children. Breast milk contains many biologically active substances that can not be included in infant formula and in respect of nutrients, although the artificial milk contain about the same amounts as milk, their quality is not equivalent $[1,2]$. The benefits of breastfeeding are also not as nutritional and a large number of publications in scientific literature show the benefits of breastfeeding on maternal health and the health, growth and development children [1]. Good start breastfeeding greatly increases the chances of well continue. And this start is dependent on conditions created around the mother, father and child [3]. The current data are sufficiently convergent research so that policies on health recommend exclusive breastfeeding for almost all children during the first six months of life [4-6]. need However, we must better understand the factors involved in the continuation or discontinuation of breastfeeding, to

${ }^{*}$ Corresponding author. develop effective strategies to promote and support breastfeeding. The practice of breastfeeding has long been recommended by international authorities had virally disappeared from the habits of the countries both industrialized and developing countries, which resulted, for mothers real difficulties in tracing movements and knowledge useful to its success. In Algeria, breastfeeding is increasingly scarce even in rural areas. Of 730,000 births, Algeria recorded 15,000 deaths of infants every year. The finding is tragic when one knows that the main cause of these casualties is the lack of breastfeeding in [7]. It is this decline in breastfeeding that pushed us to do this work whose goal is to have a clear idea about the situation in Tebessa.

\section{Methods}

\subsection{Study Population}

Tebessa or Tbessa, city of Algeria, is located $40 \mathrm{~km}$ from the Tunisian-Algerian border. Tebessa, north of Jebel Dokan, rises $960 \mathrm{~m}$ above sea level, this town in eastern 
Algeria, lies at the foot of mountains that extend Tebessa in Tunisia. Its estimated population of 190,000 inhabitants is characterized by its extreme youth and high rate of urbanization. Tebessa is the capital of the Wilaya of Tebessa whose population is estimated at nearly 520,000 inhabitants. The Wilaya of Tebessa covers an area of 13,396 sq.km.

We conducted in PMI (Mother and Child Protection) of the city of Tebessa a cross-sectional survey of 200 mothers. Before the actual survey, we conducted a pre investigation that lasted one week to test the questionnaires. The survey was conducted from 1 to May 30, 2009. Data collection was performed the day of vaccinetion of children (Sunday and Wednesday). The inclusion criterion was a mother that she would or she breastfed her child. Children have retained or received exclusive breastfeeding, mixed or artificial. In both PMI, all mothers meeting the selection criteria were set.

\subsection{Implementation of the Survey}

We conducted surveys during the interviews, using quesonnaires that included variables describing the socioecomic characteristics of the mother and father, the practice of breastfeeding and the reasons for choosing a method, the value of breast milk, the reasons for the practice or stopping breastfeeding, reasons for introducing supplementary feeding to children and the information they had about breastfeeding before delivery Additional questions been introduced such as the health of children and duraon of breastfeeding.

\subsection{Anthropometric Measurements}

Children were weighed and measured, we also measured head circumference in order to study the correlation of these anthropometric variables with breastfeeding. To measure the weight we used a baby weighs 745 SECA brand with an accuracy of $0.01 \mathrm{~kg}$ and increased to $16 \mathrm{~kg}$ for infants aged 0 - 9 months and those 18 months of small size. For infants and very agitated those 18 months and large, we used a brand SECA weighing scales with a precision of $1 \mathrm{~kg}$ and a range of $120 \mathrm{~kg}$. Measurements were made as recommended by WHO and the UN ICEF $[8,9]$. The size was measured by a telescopic measuring rod (for lack of means) brand SECA, a span of two mers and precision of $1 \mathrm{~mm}$. To measure the head circumrence, we used a dressmaker's tape measure $150 \mathrm{~cm}$ long and an accuracy of $1 \mathrm{~mm}$. BMI (Body Mass Index was calculated by the formula $\mathrm{BMI}=\mathrm{P}(\mathrm{kg}) / \mathrm{T}\left(\mathrm{m}^{2}\right)(\mathrm{p}=$ weight, $\mathrm{T}=$ size) Units.

\subsection{Stats}

The data were processed and analyzed using Epi-Info version 5, Excel and Minitab version 13. The chi-squared test was used to compare two percentages. A difference was significant for the error probability (p) below 0.05 .

\section{Results}

\subsection{Identification of Women Surveyed}

\subsubsection{Distribution of Women by Age}

In this study 200 mothers who breastfeed or who breastfed their children were interviewed (the mode of feeding is either breast or mixed or artificial). The average age of mothers was $30.66 \pm 5.76$ years ranging from 21 to 44 years (Figure 1).

\subsubsection{Distribution of Parents by Occupation and Education Level}

The majority of women surveyed are unemployed, with a proportion of $83.5 \%$ against $17.50 \%$ for fathers. Female employees account for $58.50 \%$ of our sample among fathers and $11 \%$ among mothers. Fathers are more likely to practice a profession that mothers (24\% vs. $5.5 \%$ ) Most parents in our sample have average educational level (57.50\% vs. 55.50 for father's \% mothers) (Table 1).

\subsubsection{Breastfeeding Patterns}

Breastfeeding was exclusive for $50.50 \%$ of children, mixed for $28.50 \%$ of children and artificial for $21 \%$ of children (Table 2). No significant difference was found between the mode of feeding and age of the mother.

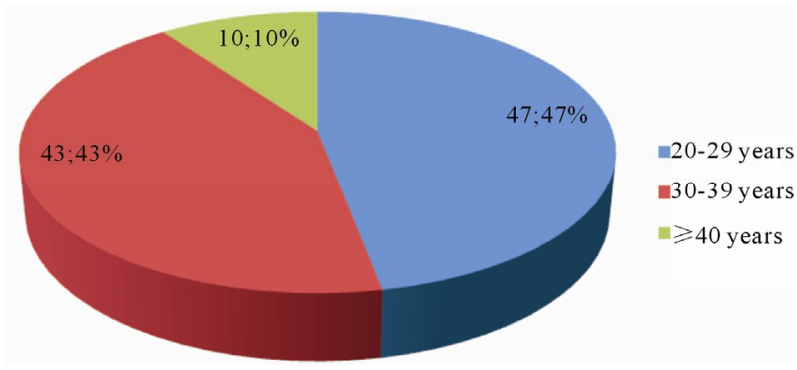

Figure 1. Distribution of mothers according to age.

Table 1. Distribution of mothers and fathers by occupation and education level.

\begin{tabular}{ccc}
\hline & Mothers & Fathers \\
\hline Occupation & \\
No occupation & $167(83.5 \%)$ & $35(17.50 \%)$ \\
Employee & $22(11 \%)$ & $117(58.50 \%)$ \\
Self-employed & $11(5.5 \%)$ & $48(24 \%)$ \\
No & Education level & \\
Primary & $32(16 \%)$ & $18(9 \%)$ \\
Average & $44(22 \%)$ & $39(19.50)$ \\
Secondary & $111(55.50 \%)$ & $115(57.50)$ \\
University & $/$ & $/$ \\
\hline
\end{tabular}


Table 2. Breastfeeding patterns.

\begin{tabular}{ccc}
\hline & Number & Frequency (\%) \\
\hline Exclusive & 101 & 50.50 \\
Joint & 57 & 28.50 \\
Artificial & 42 & 21.00 \\
Total & 200 & 100 \\
\hline
\end{tabular}

\subsection{Facilitating Factors and Binding Breastfeeding Breast}

\subsubsection{Education Level}

Exclusive breastfeeding seems to increase when the level of education of the mother decreases (50.80\% vs. $46.15 \%$, $\mathrm{p}=0.949$ ). But mixed feeding and formula feeding seems to increase as education levels increased (30.77\% vs. $28.34 \%$ and $23.08 \%$ vs. $20.86 \%$ respectively, $\mathrm{p}=$ 0.949).

Considering the father of exclusive breastfeeding and artificial seem to increase when the level of education increases ( $53.57 \%$ vs. $50 \%$ and $28.57 \%$ vs. $19.77 \%$, p = 0.326.) Conversely mixed feeding increases with education level decreases but the difference is not significant. When considering the educational level of parents, it appears that exclusive breastfeeding and artificial increase with educational level $(55.56 \%$ and $22.22 \%$ vs. $50.26 \%$ vs. $20.94 \%$ respectively p $=0.912$ ). Conversely mixed feeding seems to increase when the level of education decreased (Table 3).

\subsubsection{Parents' Occupation}

The prevalence of exclusive breastfeeding is less common for women employees $(63.64 \%$ in women who have a function cons liberal $50.90 \%$ in women without a profession and $40.91 \%$ for employees). However, artificial feeding is more prevalent among female employees (9.09\% in women who have a profession vs. $19.76 \%$ for women without a profession and $36.36 \%$ among employed mothers $\mathrm{p}=0.352$ ).

Mixed feeding is very close between the different groups. Taking into account the father's occupation shows that exclusive breastfeeding is practiced when the father is employed $(54.70 \%$ vs. $45.83 \%$ when the father has a function liberal and $42.86 \%$ when the father is unemployed $\mathrm{p}=0.09$ ). Mixed feeding is done when the householder has a function Liberal (35.42\% vs. $28.21 \%$ when the father is employed and $20 \%$ when the father has no function $\mathrm{p}=0.09$ ). Bottle-feeding is practiced when the father is unemployed (37.14\% against $18.75 \%$ when the father has a private practice and $17.9 \%$ when the father is employed $\mathrm{p}=0.09$ ).

When we considered the profession of both parents, we found no significant relationship between mode of feeding and the working mother and father. However, we found that exclusive breastfeeding is more common when one parent works $(53.19 \%$ vs. $48.28 \%$ when both parents have a profession and $40 \%$ when both parents do not work $\mathrm{p}=0.202$ ). We also found that artificial feeding is done when both parents are not $(p=0.202)$. Mixed feeding does not vary too depending on profession among different subgroups (Table 4).

Table 3. Influence the level of parental education on the mode of feeding.

\begin{tabular}{cccccc}
\hline & Exclusive & Joint & Artificial & Total & $\mathrm{p}$ \\
\hline \multicolumn{5}{c}{ Educational level of mother } \\
Low & $95(50.80 \%)$ & $53(28.34 \%)$ & $39(20.86 \%)$ & $187(100 \%)$ & 0.949 \\
High & $6(46.15 \%)$ & $4(30.77 \%)$ & $3(23.08 \%)$ & $13(100 \%)$ & \\
& & Educational level of father & \\
Low & $86(50 \%)$ & $52(30.23 \%)$ & $34(19.77 \%)$ & $172(100 \%)$ & 0.326 \\
High & $15(53.57 \%)$ & $5(17.86 \%)$ & $8(28.57 \%)$ & $28(100 \%)$ & \\
& & Educational level of parents & \\
Low & $96(50.26 \%)$ & $55(28.80 \%)$ & $40(20.94 \%)$ & $191(100 \%)$ & 0.912 \\
High & $5(55.56 \%)$ & $2(22.22 \%)$ & $2(22.22 \%)$ & $9(100 \%)$ & \\
\hline
\end{tabular}

$\mathrm{p}=$ significance level.

Table 4. Influence of parental occupation on the mode of feeding.

\begin{tabular}{|c|c|c|c|c|c|}
\hline & Exclusive & Joint & Artificial & Total & $\mathrm{p}$ \\
\hline \multicolumn{6}{|c|}{ Mother's occupation } \\
\hline No occupation & $\begin{array}{c}85 \\
(50.90 \%)\end{array}$ & $\begin{array}{c}49 \\
(29.34 \%)\end{array}$ & $\begin{array}{c}33 \\
(19.76 \%)\end{array}$ & $\begin{array}{c}167 \\
(100 \%)\end{array}$ & \\
\hline Employee & $\begin{array}{c}9 \\
(40.91 \%)\end{array}$ & $\begin{array}{c}5 \\
(22.73 \%)\end{array}$ & $\begin{array}{c}8 \\
(36.36 \%)\end{array}$ & $\begin{array}{c}22 \\
(100 \%)\end{array}$ & 0.352 \\
\hline Self-occupation & $\begin{array}{c}7 \\
(63.64 \%)\end{array}$ & $\begin{array}{c}3 \\
(27.27 \%)\end{array}$ & $\begin{array}{c}1 \\
(9.09 \%)\end{array}$ & $\begin{array}{c}11 \\
(100 \%)\end{array}$ & \\
\hline \multicolumn{6}{|c|}{ Father's occupation } \\
\hline No occupation & $\begin{array}{c}15 \\
(42.86 \%)\end{array}$ & $\begin{array}{c}7 \\
(20 \%)\end{array}$ & $\begin{array}{c}13 \\
(37.14 \%)\end{array}$ & $\begin{array}{c}35 \\
(100 \%)\end{array}$ & \\
\hline Employee & $\begin{array}{c}64 \\
(54.70 \%)\end{array}$ & $\begin{array}{c}33 \\
(28.21 \%)\end{array}$ & $\begin{array}{c}20 \\
(17.09 \%)\end{array}$ & $\begin{array}{c}117 \\
(100 \%)\end{array}$ & 0.09 \\
\hline Self-occupation & $\begin{array}{c}22 \\
(45.83 \%)\end{array}$ & $\begin{array}{c}17 \\
(35.42 \%)\end{array}$ & $\begin{array}{c}9 \\
(18.75 \%)\end{array}$ & $\begin{array}{c}48 \\
(100 \%)\end{array}$ & \\
\hline \multicolumn{6}{|c|}{ Parental occupation } \\
\hline One Works & $\begin{array}{c}75 \\
(53.19 \%)\end{array}$ & $\begin{array}{c}42 \\
(29.79 \%)\end{array}$ & $\begin{array}{c}24 \\
(17.02 \%)\end{array}$ & $\begin{array}{c}141 \\
(100 \%)\end{array}$ & \\
\hline Both work & $\begin{array}{c}14 \\
(48.28 \%)\end{array}$ & $\begin{array}{c}8 \\
(27.59 \%)\end{array}$ & $\begin{array}{c}7 \\
(24.14 \%)\end{array}$ & $\begin{array}{c}29 \\
(100 \%)\end{array}$ & 0.202 \\
\hline $\begin{array}{c}\text { The two do not } \\
\text { work }\end{array}$ & $\begin{array}{c}12 \\
(40 \%)\end{array}$ & $\begin{array}{c}7 \\
(23.33 \%)\end{array}$ & $\begin{array}{c}11 \\
(36.67 \%)\end{array}$ & $\begin{array}{c}30 \\
(100 \%)\end{array}$ & \\
\hline
\end{tabular}

$\mathrm{p}=$ significance level . 
Highlight author and affiliation lines of affiliation 1 and copy this selection.

Formatting: Affiliation 2 must immediately follow affiliation 1 . The additional affiliations follow one an- other.

\subsubsection{Sources of Knowledge of Mothers on Breastfeeding}

Among the factors that facilitate breastfeeding, family (mother, friends, spouse ...) leads with $53.47 \%$, followed by documents with $23.76 \%, 21.78 \%$ the consultant, the midwife with $11.88 \%$ and the role of the media with $7.92 \%$. On method of feeding, influenced by the entourage of women, a significant difference was found. $53.47 \%$ of women chose exclusive breastfeeding, 38.60\% mixed breastfeeding and $33.33 \%$ preferred to breastfeed their children through a formula $(\mathrm{p}=0.046)$ (Figure 2).

\subsubsection{First Feed Given to the Child in the First Hour after Birth}

The first food given to the newborn at birth: breast milk with $66.5 \%, 16.5 \%$ sugar water, tea $12 \%, 7 \%$ simple water and artificial milk last position with $4 \%$ (Figure 3).

\subsubsection{Causes Stop Breastfeeding}

Figure 4 shows that twenty-one percent (21.42\%) of

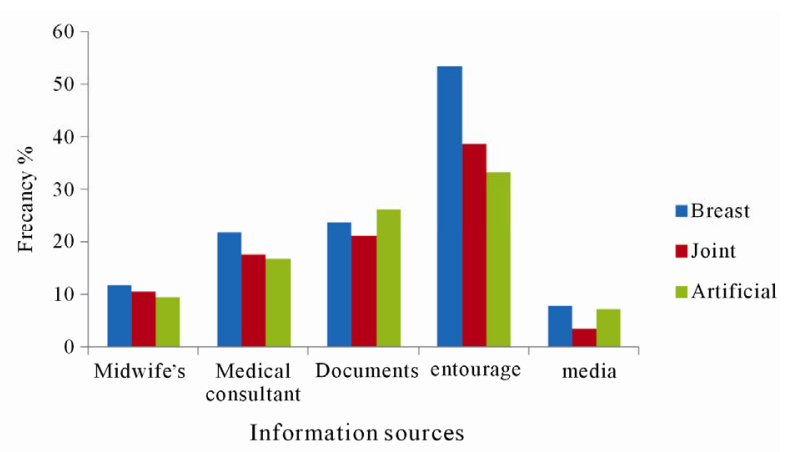

Figure 2. Importance of breastfeeding patterns according to the sources of knowledge mothers in relation to breastfeeding.

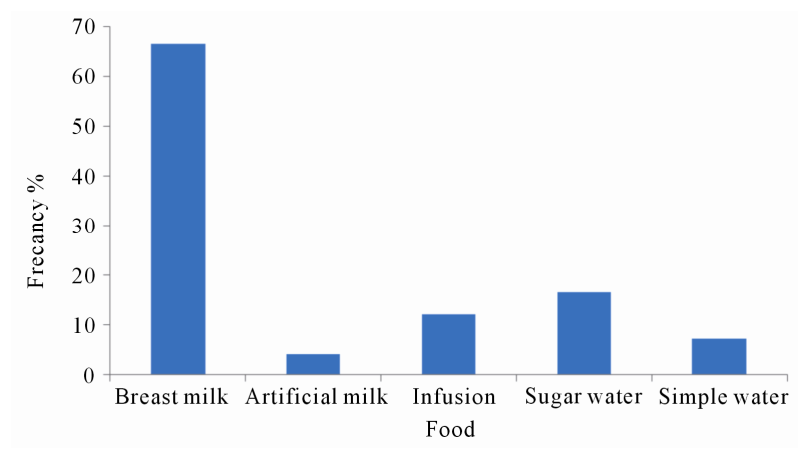

Figure 3. First food given to the child in the first hour after birth. women said that the reason for stopping breastfeeding is the health status of women (16.66\%) of the mothers confirmed that the main cause of cessation of breastfeeding is insufficient milk, return to work represents (14.28\%), the aesthetic of women and the occurrence of another pregnancy (11.90\%) and with modernism (2.38 \%).

\subsubsection{Reasons for Choice of Breastfeeding}

The majority of women surveyed $(72.78 \%)$ stated that breast milk is best for the child's health, which is why it is chosen as the mode of feeding. Other reasons were cited by mothers such as beneficial for the mother (13.92\%) no idea $(10.12 \%)$ or lack of money to buy formula milk (3.16\%) (Figure 5).

\subsubsection{Duration of Breastfeeding}

Of the 200 children selected for this survey, 40 of them are no longer breastfed until the age of 6 months. The average duration of breastfeeding in our sample is (4.68 \pm 4437 months) on the day of the survey, with a minimum of one month and one, maximum of 23 months. We found no correlation between BMI and duration of breastfeeding. Any time a positive correlation was observed between the child's current weight and duration of breastfeeding ( $r=0.653, p=0.001)$, the child's current size and duration of breastfeeding $(r=0.544, p=0.001)$ and head circumference and duration of breastfeeding $(\mathrm{r}$ $=0.557, \mathrm{p}=0.001)$.

\section{Discussion}

The objective of this study is to identify the factors fa-

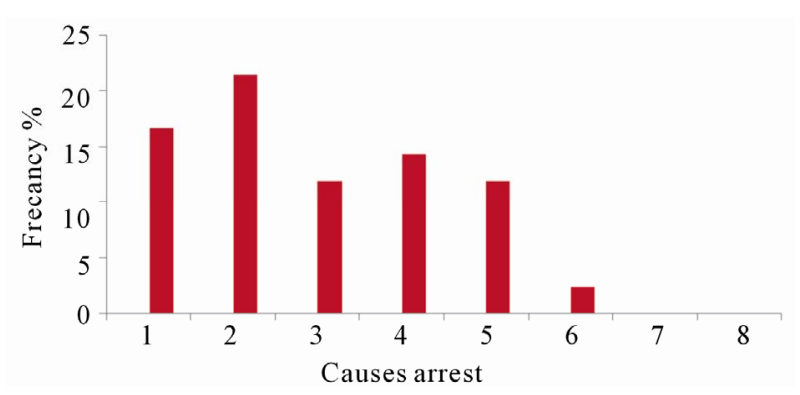

Figure 4. Reasons for stopping breastfeeding.

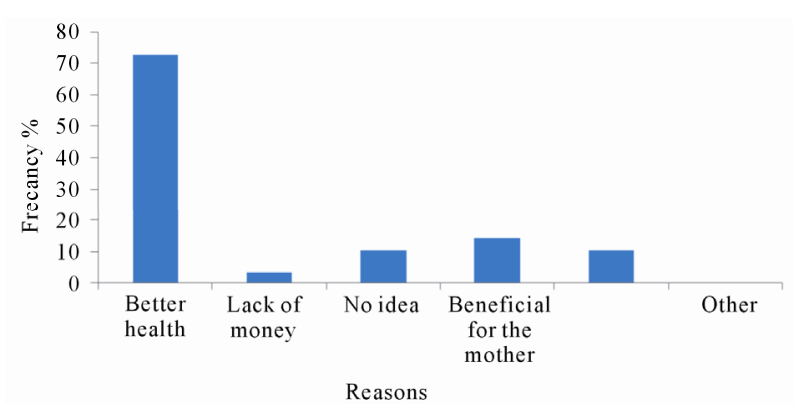

Figure 5. Reasons for the choice of breastfeeding. 
cilitating and constraining breastfeeding in a town in eastern Algeria. This study provides data on 200 women and their children from consulting in both PMI chosen to make this work. This work has limitations that should be emphasized. The forgotten women for some answers.

\subsection{Identification of Women Surveyed}

According to our results, the average age of the women surveyed was $30.66 \pm 5.76$ years, with extremes of 21 and 44 years. These results are similar to those found by Sepou A. et al. 2001 [10]. The majority of women in our sample are unemployed, with a proportion of $83.5 \%$. Female employees account for $11 \%$. In a study in Gitwe $91 \%$ of women are farmers cons $1 \%$ without occupation [11]. Most mothers in our sample have average educational level $(55.50 \%)$ the upper level is the least represented (6.5\%). These results disagree with those observed in the study Gitwe [11] where the majority of pregnant women are farmers, with a proportion of $91 \%$. The officials represent only $4 \%$. Most of the mothers of this work are illiterate with $55 \%$, the average level is represented with less than $4 \%$.

\subsection{Facilitating Factors and Binding Breastfeeding Breast}

\subsubsection{Prevalence of Breastfeeding}

Exclusive breastfeeding provides the optimal development of infants up to 6 months. Exclusive breastfeeding protects the newborn from gastrointestinal infections, and to a lesser extent, ENT and respiratory infections. The protective effect of breastfeeding depends on its duration and its exclusivity [12]. In this study it appears that the prevalence of exclusive breastfeeding was $50.50 \%$ followed by mixed breastfeeding for $28.50 \%$ of children and in last place artificial feeding for $21 \%$ of children. The exclusive breastfeeding are relatively few, including some countries where the majority of breastfed babies are: in Algeria " $7 \%$ of women exclusively breastfeed their babies after six months [7], in Turkey, only $14 \%$ of babies of 4 months are exclusively breastfed, while $14 \%$ of babies are still breastfeeding at 20 months. Recall that the recommendations of WHO (World Health Organization) and UNICEF (United Nations Fund for Children) are the following - Exclusive breastfeeding from birth to approximately 6 months - continued breastfeeding children until their second year or more, while providing appropriate complementary foods [13].

\subsubsection{Education Level}

In this exclusive breastfeeding appears to increase when the level of education of the mother decreases $(50.80 \%$ vs. $46.15 \%, 0.949$ ). But mixed feeding and formula feeding increase as educational level increases $(30.77 \%$ vs.
28.34\% and $23.08 \%$ vs. $20.86 \%$ respectively ( $=0.949$ ). In a study conducted in Morocco among 220 mothers, the level of maternal education plays a very significant (p $<0.05$ ) on the mode of breastfeeding, the prevalence is higher (84.2\%) among illiterate than among educated (70.9\%) [14]. ANAES Conversely indicates that breastfeeding is more common among women belonging to privileged backgrounds and have made further studies [12]. A similar result was reported in a study by ORS Alsace 2000 [15].

Taking into account the level of education of the father of exclusive breastfeeding and artificial increase when the educational level increases $(53.57 \%$ vs. $50 \%$ and $28.57 \%$ vs. $19.77 \%$, p $=0.326$ ), conversely mixed feeding increases as the level education decreases but the difference is not significant.

\subsubsection{Parental Occupation}

According to our results, exclusive breastfeeding is less common for female employees $(63.64 \%$ in women who have function cons liberal $50.90 \%$ in women without a profession and $40.91 \%$ for employees). Similar findings were made in Morocco where the housewives (84.7\%) than lactating women in employment (40\%) [14]. Similar results were observed in a study in Luxembourg that exclusive breastfeeding is practiced by non-active women (18\% vs. 8.4\%) [16]. However, artificial feeding is more prevalent among female employees $(9.09 \%$ in women who have a profession vs. $19.76 \%$ for women without a profession and $36.36 \%$ among employed mothers $\mathrm{p}=$ 0352). Mixed feeding is very close between the different groups. The working conditions of many mothers in some developed countries do not favor the continuation of breastfeeding.

According to our results on socio-economic status of parents (education and occupation) do not influence the mode of feeding. A similar result was observed by FSaadi Bellati [14]. According to Jane A Scott et al. [17] many studies have shown a link between social class and breastfeeding. In Australia, social class and breastfeeding are positively associated. Similar results were reported in England, New Zealand, Denmark, Sweden, Finland, Switzerland, Canada and the USA.

\subsubsection{Sources of Information for Mothers on Breastfeeding}

According to the results of this work, the environment comes first with $53.47 \%$, followed by documents with $23.76 \%$, $21.78 \%$ the consultant, the midwife with $11.88 \%$ and the role of the media with $7.92 \%$. Breastfeeding patterns and significantly influenced by the surroundings of the mother. $53.47 \%$ of women chose exclusive breastfeeding, 38.60\% mixed breastfeeding and 33.33\% chose to breastfeed their children through a formula $(\mathrm{p}=0.046)$. 
Other authors have shown that support from partner, family and friends are factors that influence breastfeeding initiation and duration. The attitude of the partner plays a very important role in the decision to breastfeed and to wean.

In the absence of extended family (as is the case among couples immigrants), mothers rely heavily on the partner. A U.S. study showed that the opinion of the father, after adjusting for maternal age, level of education, ethnicity and marital status was the most important factor. This is confirmed by a recent study in Australia) [17]. Another author showed that in case of problems with breastfeeding, it is the family and friends that women were addressed first (34.7\%), then to lactation consultants $(16.5 \%)$, pediatrician (8.8\%), the obstetrician or midwife (8.2\%), support group for breastfeeding (5.9\%) and motherhood (2.5\%) [18].

\subsubsection{First Feed Given to the Child}

Our results showed that the first food given to the child in the first hour after birth: mother's milk was with $66.5 \%$, followed by $16.5 \%$ sugar water, tea $12 \%, 7 \%$ and simple water last position in the formula with $4 \%$. Similar results were observed in Bangui [10]. Within 24 hours after childbirth, all mothers initiate breastfeeding, except those who underwent caesarean section [19].

\subsubsection{Reasons for Stopping Breastfeeding}

Breastfeeding usually creates between mother and child relationship serene and quiet complicity. However, some situations that make breastfeeding difficult and even hinder their pursuit. It is usually difficult simple, easy to resolve through patience and know-how from the healthcare professional. These difficulties can be linked to either the mother or the baby or the environment. According to our results, $21.42 \%$ of women said that the reason for stopping breastfeeding was the health status of women $(16.66 \%)$ of the mothers confirmed that the main cause of stopping breastfeeding was insufficient milk. Returning to work is (14.28\%), the aesthetics of women and the occurrence of another pregnancy (11.90\%) and with modernism (2.38\%).

These cases have been observed by other authors $[16,20]$. ORS 2000 [15] showed that lack of milk is the most frequently cited causes of weaning (40\% before action, $30 \%$ after) and the resumption of work is cited in more than a quarter of cases. In open comments, many note that mothers returning to work has led to a "decrease in the quantity of milk. "More than one in 2 (55\%) believe that a longer maternity leave would encourage breastfeeding longer. Thus the cessation of breastfeeding is still too often the rule, arises when an infectious disease in the mother or child, for fear that the prescribed treatment is not harmful to the child or that the maternal disease is not him transmitted [21]. It is the duty of all to work to address these major causes of failure of breastfeeding.

\subsubsection{Reasons for Choice of Breastfeeding}

The majority of women interviewed in this study (72.78\%) said they chose milk because it is better for the health of the child. Beneficial for the mother (13.92\%) no idea $(10.12 \%)$ or lack of money to buy formula milk (3.16\%) are also significant causes have been cited in this work. The same observations were made in a study in Bangui and Bossangoa Central [10].

\subsubsection{Duration of Breastfeeding}

According to WHO, "Breastfeeding is the best way to provide infants the nutrients they need for healthy growth and development. "Breast milk contains nutrients ideal for digestion, brain development and proper growth. It transmits the antibodies from mother to baby, helping it to protect themselves from infection and disease [22]. In our work, the average duration of breastfeeding is (4.68 \pm 4437 months) on the day of the survey, with a minimum of one month and one, maximum of 23 months. In a study conducted in Alsace, the average duration of breastfeeding was 9 weeks for mothers who breastfeed for the reception of the questionnaire, either "before" or "after" the action [15].

In affluent backgrounds, a study conducted in 1980 [19] with women with a monthly family income exceeds $500 \mathrm{FF}$ and having done graduate studies showed that the average duration of breastfeeding was 14 months. $60 \%$ of them were breastfeeding on demand during the first six months of life (90\% urban poor) [19].

Thus, different factors such as psychosocial, emotional, cognitive, behavioral, political, etc. may have an impact on the decision to feed her baby breast or bottle feeding at birth, and duration of breastfeeding. It appears that early cessation of the stems more difficulty with breastfeeding, including lack of information and support, that woman's choice.

\section{Conclusions}

The results of this study allowed us to draw some conclusions: Breastfeeding (exclusive) is performed in $50.50 \%$ the day of the survey, the breastfeeding rates were lowest among working mothers $40.91 \%$, exclusive breastfeeding appears to increase when the level of education of the mother decreases (50.80\% vs. 46.15\%), mixed feeding and formula feeding seems to increase when the educational level increases (30.77\% vs. 28.34\% and $23.08 \%$ vs. $20.86 \%$ respectively, the socio-economic status of parents do not influence the mode of feeding, the environment plays an important role in the choice of 
breastfeeding with $53.47 \%$ of cases, followed by documents with $23.76 \%, 21.78 \%$ the consultant, the midwife with $11.88 \%$ and finally the media with $7.92 \%$. The first food given to the child in the first hour after birth: mother's milk was with $66.5 \%$, followed by $16.5 \%$ sugar water, tea $12 \%, 7 \%$ simple water and artificial milk last position with $4 \%$.

The main causes of the cessation of breastfeeding mothers surveyed cited by decreasing order, are: health status of women, insufficient milk, return to work the aesthetics of women and the occurrence a new pregnancy. The majority of women interviewed in this study (72.78\%) said they chose milk because it is better for the health of the child. Other causes have been cited as beneficial for Mom, no idea or no money to buy formula milk. The average duration of breastfeeding is (4.68 \pm 4.437 months) on the day of the investigation.

Efforts to promote breastfeeding in Algeria are necessary to certain subgroups of the population as to the health professionals. Development of the health culture of the child and mother. The organization of maternity must enable support for breastfeeding and avoid practices that may impede it.

\section{REFERENCES}

[1] S. Dionne, S. Jeff, L. Guay, et al., "Breastfeeding in Quebec: The Guidelines,” Ministry of Health and Human Services, Quebec, 2001.

[2] B. Beaufrère, J. L. Bresson, A. Briend, et al., "The Promotion of Breastfeeding: It's also the Matter of Pediatricians," Archives of Pediatrics, Vol. 7, 2000, pp. 11491153.

[3] L. Girard and M. Landais, "The Nursery Nurse in the Maternity and Breastfeeding-Books of Nursery,” No. 206, 2007, pp. 9-25.

[4] WHO (World Health Organization), "Infant and Young child. World Health Assembly in 2002,” WHO, Geneva, 2002.

[5] American Academy of Pediatrics Workgroup on Breastfeeding, "Breastfeeding and the Use of Human Milk," Pediatrics, Vol. 115, No. 2, 2005, pp. 496-506. doi:10.1542/peds.2004-2491

[6] Health Canada, Duration of Exclusive Breastfeeding, "Health Canada Recommendations,” Health Canada, Ottawa, 2004.

[7] L. Bedar, “The daily L'Expression,” Daily Algeria, Edition of 11 November 2008.

[8] WHO, "Measuring Change in Nutritional Status," WHO, Geneva, 1983, 104 Pages.

[9] UNICEF, "National Survey of the Objectives of the MDG Mid-Decade Algeria 1995," United Nations Fund for Children World Health Organization United Nations
Fund for the Population, UNICEF, Algiers, 1996.

[10] A. Sepou, M. C. Yanza, E. Nguembi, et al., "What Is the Value of Breastfeeding Did in Urban and Semi-Urban Central?” Book Study and Research French/Health, Vol. 11, No. 2, 2001, pp. 85-89.

[11] A. Ngarambe, "Assessment of the Level of Knowledge of Pregnant Women about Breastfeeding, if the Health Center Gitwe [Thesis Study]," Institute of Education GitwaA1, 2006.

[12] ANAES (National Agency for Accreditation and Evaluation in Health), "Breastfeeding Implementation and Continued in the First 6 Months of Life of Children Recommendations in May 2002,” Service Ecommendations and Professional References.

[13] Association IPA Information Pour l'Allaitement maternel, "General Information about Breastfeeding, The Current Situation: Figures and Statistics,” Source IPA June 2001.

[14] F. Bellati-Saadi, M. G. Sall, S. L. Martin, et al., "Current Status of Breastfeeding in the Region of Agadir in Morocco about a Survey among 220 Mothers," Medicine of Black Africa, Vol. 43, No. 4, 1996, pp. 94-96.

[15] Alsace ORS, "Evaluation of an Action to Promote Breastfeeding in Alsace in 2000,” 63 Pages Full Report, Regional Observatory of Health in Alsace, France.

[16] Department of Health-Department of Health Division of Preventive Medicine 2004 Luxembourg, "Breastfeeding in Luxembourg Survey on the Prevalence and Factors Associated with Breastfeeding from Birth to 6 Months,"

[17] A. Jane Scott and W. Colin Binns, "Studies in Industrialized Countries, Factors Associated with Initiation and Duration of Breastfeeding: A Review of the Literature," Australian Journal of Nutrition and Dietetics, Vol. 55, No. 2, 1998, pp. 51-61.

[18] S. Arora, C. L. McJunkin, J. Wehrer, et al., "Major Factors Influencing Breastfeeding Rates: Mother's Perception of Father's Attitude and Milk Supply,” Pediatrics, Vol. 106, No. 5, 2000, Electronic Version of 5 Pages.

[19] C. Munyanshongore, "Breastfeeding in Urban and Rural Rwanda," PhD Thesis in Public Health, Free University of Brussels, Brussels, 1984.

[20] A. Barkat, A. Lyaghfouri, A. Mdaghri Alaoui, et al., “Thinking about Breastfeeding in Morocco," Guide to Medicine and Health in Morocco, 15 July 2004.

[21] G. Gremmo-Feger, M. Dobrzynski and M. Collet, "Breastfeeding and Drugs," Journal of Gynecology, Obstetrics and Reproductive Biology, Vol. 32, No. 5, 2003, pp. 466475.

[22] Canadian Paediatric Society, Dietitians of Canada, Health Canada, "The Benefits of Breastfeeding Infants in Canada in Nutrition for Term Infants and Health, Ottawa (Ontario)," Department of Public Works and Government Services of Canada, 2005, Accessed on 15 April 2009. http://www.hc-sc.gc.ca/fn-an/pubs/infant-nourrisson/nut_i nfant_nourrisson_term_3-fra.php 